\title{
ARTICLE \\ Impact of Compaction Mode on Strength Properties of Sustainable Asphalt Concrete
}

\author{
Saad Issa Sarsam" \\ Sarsam and Associates Consult Bureau SACB, Baghdad, Iraq
}

\section{ARTICLE INFO}

Article history

Received: 19 August 2021

Accepted: 2 November 2021

Published Online: 5 November 2021

Keywords:

Sustainable asphalt concrete

Compaction mode

Tensile

Shear strength

Marshall stiffness

\begin{abstract}
Various modes of compacting the asphalt concrete mixture can create mechanically different behaviour of the prepared specimens and can alter its sustainability. An attempt has been made in the present assessment to prepare asphalt concrete specimens by implementation of three modes of compaction, the gyratory, the roller, and the Marshall hammer. The specimens were prepared at the target bulk density of Marshall method at optimum asphalt content. Extra specimens were prepared at $0.5 \%$ asphalt below and above the optimum. Core specimens have been obtained from the roller compacted slab samples. The specimens were tested for the Marshall stiffness, tensile, and shear strength. It was observed that at optimum asphalt content, the indirect tensile strength declines by (18.8 and 70.5$) \%$ for gyratory and roller compacted specimens respectively as compared with hammer compacted specimens. At optimum asphalt content, the shear strength declines by (70.5 and 82.2) \% while Marshall stiffness declines by (10.2 and 44.8) \% for hammer and roller compacted specimens as compared with that of gyratory compacted specimen. Specimens prepared by gyratory compaction are less susceptible to the change in the testing temperature as compared with other modes of compaction. It is recommended to consider the mode of compaction to suit the required design property of sustainable asphalt concrete mixture.
\end{abstract}

distributions and orientations of shapes of voids and aggregate particles as addressed by Hartmán et al. ${ }^{[1]}$. The influence of various laboratory compaction procedures (Marshall, vibrating hammer, roller, and gyratory) on the fatigue properties and indirect tensile stiffness of bituminous mixtures was investigated. It was observed that the lower stiffness specimens were produced by

*Corresponding Author:

Saad Issa Sarsam,

Sarsam and Associates Consult Bureau SACB, Baghdad, Iraq;

Email: saadisasarsam@coeng.uobaghdad.edu.iq 
roller compaction method. The impact of the compaction methods on the fatigue strength of asphalt concrete mixtures is considered as mixture dependent. Asphalt concrete mixtures with grading profiles that are designed for aggregate interlock were found to have higher fatigue strengths, provided that the materials were compacted with the aid of a method that could facilitate reorientation of the aggregate particles. Vacková et al. ${ }^{[2]}$ revealed that insufficiently compacted asphalt concrete layers are more susceptible to more intensive asphalt oxidation and deeper water penetration which aids to faster surface degradation. However, the excessively compacted asphalt pavements are more susceptible to low-temperature cracking and permanent deformations. It was reported that the mode of compaction of asphalt concrete is a significant factor which enhance the strength properties, durability, and resistance to cracking. Specimens were compacted using different compaction energies for evaluating the influence of poor compaction on the asphalt concrete properties. The specimens were compacted by Marshall hammer with different amounts of blows. The stiffness modulus at four testing temperatures was measured. The result exhibits very strong dependence between compaction rate and decrease of stiffness modulus. Huang et al. ${ }^{[3]}$ constructed asphalt concrete test sections of pavement by implementing static, vibratory, and semi-staticvibratory rolling at various compaction repetitions. The effects of the rolling methods in the field, cooling time, and compaction numbers on asphalt concrete pavement were investigated. It was revealed that, if the asphalt concrete pavement is opened to traffic and the strength development and stability of asphalt concrete are simultaneously considered, the pavement should first be compacted with the aid of vibratory rollers, followed by static rollers to complete the construction of the pavement. Xing et al. ${ }^{[4]}$ stated that the number of contact points, structure of the aggregate, and orientation of the aggregate particles is dependent on the conditions and compaction methods. Correlations between the obtained strength results and compaction methods were observed. The strength of the asphalt concrete is directly related to its compaction process, which can significantly affect the overall properties of the asphalt mixture. It was concluded that the difference in strength may be related to the change in aggregate interlock pattern in the specific compaction method. Airey and Collop ${ }^{[5]}$ revealed that the laboratory compaction methods can differ in many parameters, such as the compaction time, the pressure force and the way the force is transmitted, and the final shape of the obtained asphalt concrete sample and the aggregate particles orientation inside.
Marcobal et al. ${ }^{[6]}$ assessed three laboratory compaction methods (Marshall impact hammer, gyratory compactor, and static load) and defined the most suitable compaction testing technique for asphalt mixtures. The mechanical characteristics of the asphalt mixture performance was conducted to quantify the stiffness modulus, Indirect Tensile Strength (ITS), four-point bending fatigue, and rutting test. Mixtures with $100 \%$ Reclaimed Asphalt Pavement (RAP) and emulsified bitumen exhibited proper mechanical and volumetric behavior in terms of rutting resistance, moisture damage, fatigue cracking, ITS, stiffness modulus. Tarefder and Ahmad ${ }^{[7]}$ assessed the structure of asphalt concrete compacted by linear kneading compactor, gyratory compactor, and field cores. The variations of moisture damage and permeability of samples prepared by various compaction procedures were compared. It was noticed that the structure of field compacted asphalt concrete samples is totally different from gyratory compacted and linear kneading compacted asphalt samples. The indirect tensile strength of field samples is always less than gyratory samples and more than linear kneading compacted samples. Linear kneading compacted samples and field samples are shown to be more susceptible to moisture than the gyratory compacted samples. Woszuk and Franus ${ }^{[8]}$ revealed that under the laboratory conditions, specimens of asphalt concrete can be compacted in different ways, depending on type of tests, the type of technology used, the purpose of the sample, and the applicable regulations. The most used devices are Marshall compactor, gyratory compactor, vibrating compactor, and asphalt roller compactor. Radzi et al. ${ }^{[9]}$ stated that the laboratory compaction for asphalt concrete specimen compaction and fabrication is expected to simulate the properties of the asphalt concrete pavement in the field. It is desirable that the laboratory compaction of asphalt concrete specimens should be a true indicator of field performance of the mixture regarding air voids content, particle orientation, permeability, and mechanical properties. Pérez-Jiménez et al. ${ }^{[10]}$ revealed that the influence of compaction procedures using Marshall compactor and Superpave gyratory compactor on mechanical and volumetric properties of asphalt mixture indicated that it is not wise to set up several gyrations to compact the asphalt concrete specimens with a target bulk density that is like to the obtained one through Marshall compaction technique because the number of loading cycles varies depending on the asphalt mixture type. Cheung and Dawson ${ }^{[1]}$ addressed that the general aggregate structure and the aggregate particles orientation are significantly different in specimens compacted by various methods. The roller compacted asphalt concrete 
slab samples are characterized by the aggregate particle size distribution across. However, the samples produced using other laboratory compaction methods of specimens in the mold are susceptible to circumferential particle orientation. Interlocking and contact of aggregates, based on the shape of the aggregate, also has a significant impact on the compaction. Using angular aggregate particles leads to exhibit more uniform distribution of aggregates contact points and internal forces, with a better interconnection between elements and improvement to permanent deformation and fatigue performance resistance. Wróbel et al. ${ }^{[12]}$ revealed that the undercompacted asphalt concrete mixes are characterized by their lowest stiffness modulus and lowest indirect tensile strength regardless of the test temperature. The indirect tensile strength ratio was the lowest for those asphalt concrete samples, which confirms that the insufficiently compacted asphalt layers could be more susceptible to water and frost. The increased air voids content due to lower compaction can cause premature degradation of the asphalt concrete pavement. However, over-compaction is particularly dangerous. There may cause loosening of the aggregate and damage to their contact points, which can result in reduced resistance to the weathering and can lead to the destruction of the road surface. Reduction in the strength and the stiffness for over-compacted specimens could be detected.

The aim of the present investigation is assessing the influence of three modes of compaction namely (Marshall, gyratory, and roller) on the strength properties (punching shear strength, indirect tensile strength, and Marshall stiffness) of the asphalt concrete mixtures prepared at three various percentages of asphalt binder by weight of aggregates. Consideration of the mode of compaction to suit the required design property can support obtaining a sustainable asphalt concrete mixture.

\section{Materials Characterizations}

The materials used in the present investigation are usually used by roadway agencies for asphalt pavement construction in Iraq.

\subsection{The Asphalt Cement Binder}

The asphalt binder used in this investigation has a penetration grade of 40-50. It was obtained from Dourah oil refinery. Physical properties of the asphalt cement are listed in Table 1.

\subsection{The Fine and Coarse Aggregates}

The crushed coarse aggregates which has a nominal maximum size of $12.5 \mathrm{~mm}$ were obtained from AL-Nibae quarry, the fine aggregates are also obtained from the same source. A typical dense gradation as per the State Commission for Roads and Bridges, SCRB ${ }^{[14]}$ usually implemented for wearing course layer was employed. The physical properties of the fine and coarse aggregates are listed in Table 2.

Table 1. The Physical properties of Asphalt Binder according to ASTM ${ }^{[13]}$

\begin{tabular}{cccc}
\hline Property & Testing conditions & $\begin{array}{c}\text { ASTM } \\
\text { Designation }\end{array}$ & $\begin{array}{c}\text { Test } \\
\text { results }\end{array}$ \\
\hline Penetration & $25^{\circ} \mathrm{C}, 100$ gm.,5 Seconds, \\
$(1 / 10 \mathrm{~mm})$ & D 5 & 41 \\
$\begin{array}{c}\text { Softening } \\
\text { point }\end{array}$ & Ring and ball & D 36 & 49 \\
$\begin{array}{c}\text { Ductility } \\
\text { Specific } \\
\text { gravity }\end{array}$ & $25^{\circ} \mathrm{C}, 5 \mathrm{Cm} /$ minutes & D 113 & +150 \\
Flash point & Cleveland open cup & D 70 & 1.01 \\
\hline
\end{tabular}

Table 2. The Physical properties of coarse and fine aggregates according to ASTM ${ }^{[13]}$

\begin{tabular}{ccccc}
\hline \multirow{2}{*}{ Physical properties } & \multicolumn{2}{c}{ Coarse aggregates } & \multicolumn{2}{c}{ Fine aggregates } \\
\cline { 2 - 5 } & $\begin{array}{c}\text { ASTM } \\
\text { Designation }\end{array}$ & $\begin{array}{c}\text { Test } \\
\text { results }\end{array}$ & $\begin{array}{c}\text { ASTM } \\
\text { Designation }\end{array}$ & $\begin{array}{c}\text { Test } \\
\text { results }\end{array}$ \\
\hline $\begin{array}{c}\text { Bulk specific gravity } \\
\text { Apparent specific } \\
\text { gravity }\end{array}$ & C 127 & 2.584 & C 128 & 2.604 \\
$\begin{array}{c}\text { Water absorption \% } \\
\begin{array}{c}\text { Wear - Los Angeles } \\
\text { abrasion \% }\end{array}\end{array}$ & C 127 & 2.608 & C 128 & 2.664 \\
\hline
\end{tabular}

\subsection{The Mineral Filler}

Ordinary Portland cement was obtained from Tasluga cement plant and implemented as mineral filler; the physical properties of the mineral filler implemented are listed in Table 3.

Table 3. The Physical properties of the filler

\begin{tabular}{cc}
\hline Property & Test results \\
\hline Specific gravity & 3.14 \\
Specific surface area $\left(\mathrm{m}^{2} / \mathrm{kg}\right)$ & 355 \\
Percent passing sieve No. 200 & 96 \\
\hline
\end{tabular}

\subsection{Selection of Asphalt Concrete Aggregates Gradation}

Asphalt concrete with dense gradation is usually used for wearing course as per State Commission for Roads and Bridges SCRB ${ }^{[14]}$ specification. The aggregates which have $12.5 \mathrm{~mm}$ nominal maximum size has been implemented. Table 4 exhibits the selected aggregates 
gradation and the SCRB ${ }^{[14]}$ specification limits.

Table 4. Combined Gradation of Aggregates for Wearing Course as per SCRB ${ }^{[14]}$

\begin{tabular}{|c|c|c|c|c|c|c|c|}
\hline Sieve size $(\mathrm{mm})$ & 19 & 12.5 & 9.5 & 4.75 & 2.36 & 0.3 & 0.75 \\
\hline $\begin{array}{l}\text { Selected aggregates } \\
\text { gradation }\end{array}$ & 100 & 95 & 83 & 59 & 43 & 13 & 7 \\
\hline $\begin{array}{l}\text { SCRB, }{ }^{[14]} \text { Specification } \\
\text { limits }\end{array}$ & 100 & $\begin{array}{l}90- \\
100\end{array}$ & $\begin{array}{c}76- \\
90\end{array}$ & $\begin{array}{c}44- \\
74\end{array}$ & $\begin{array}{c}28- \\
58\end{array}$ & $5-12$ & $4-10$ \\
\hline
\end{tabular}

\section{Testing Methods}

\subsection{Preparation and Compaction of Asphalt Concrete Specimens by Marshall Hammer Method}

Fine and Coarse aggregates were combined with the required amount of filler to meet the SCRB, ${ }^{[14]}$ specification for wearing course. The combined aggregates were heated to $160^{\circ} \mathrm{C}$ while the asphalt binder was heated to $150^{\circ} \mathrm{C}$. The combined aggregates and asphalt binder were mixed thoroughly until the aggregates get coated with thin film of the asphalt binder and were ready for the compaction process. The compaction process starts after pouring the hot mix asphalt concrete into the Marshall mold of $63.5 \mathrm{~mm}$ in height and $101.6 \mathrm{~mm}$ in diameter. The mixture was subjected to 75 blows of the Marshall hammer on each side of the specimen. The compacted specimens were left to cool at laboratory environment for 24 hours then the specimens were extruded from the mold. Specimens were prepared at optimum binder content of $4.7 \%$ and at $0.5 \%$ asphalt below and above the optimum binder requirements. Specimens were subjected for strength properties determination such as Marshall stiffness which was calculated by dividing the Marshall stability in $(\mathrm{kN})$ by Marshall flow in $(\mathrm{mm})$, indirect tensile strength ITS $(\mathrm{kPa})$, and double punching shear strength $(\mathrm{kPa})$. Details of obtaining the optimum binder content could be referred to Sarsam and Al-Obaidi ${ }^{[15]}$. Specimens were tested in triplicate and the average value of each strength test was considered for analysis.

\subsection{Preparation and Compaction of Asphalt Concrete Specimens by Gyratory Compaction Method}

The Gyratory compaction technique was adopted to prepare the required asphalt concrete specimens at the target density of the Marshall specimens for the three percentages of asphalt binder. Specimens were prepared using (148) gyrations, which was obtained after many trials. The procedure for preparation of asphalt concrete mixtures was as that of Marshall mixtures. The mold with the asphalt mixture was assembled into the Gyratory compactor machine and centered under the loading ram. The gyrations starts and the ram extends down into the mold and touches the specimen. The ram stops when the pressure reaches $600 \mathrm{kPa}$. After feeding the necessary information concerning the specimen to the software, and implementing the gyration angle of $\left(1.25^{\circ}\right)$, the compaction process of the specimen started. When the specimen reaches the specified height with the design number of gyrations, the compaction process stops automatically. The mold will be discharged from the device. The specimen with $63.5 \mathrm{~mm}$ in height and 101.6 $\mathrm{mm}$ in diameter is extracted from the mold and left to cool at room temperature for 24 hours. Specimens were prepared at optimum binder content of $4.7 \%$ and at $0.5 \%$ asphalt below and above the optimum. Specimens were subjected for strength properties determination such as Marshall stiffness which was calculated by dividing the Marshall stability in $(\mathrm{kN})$ by the Marshall flow in $(\mathrm{mm})$, indirect tensile strength ITS $(\mathrm{kPa})$, and double punching shear strength $(\mathrm{kPa})$. Details of the gyratory compaction trials could be found at Sarsam and Al-Obaidi ${ }^{[16]}$. Specimens were tested in triplicate and the average value of each strength test was considered for analysis.

\subsection{Preparation and Compaction of Asphalt Concrete Specimens by Roller Compaction Method}

Based on the target density of Marshall specimens and its asphalt content, the required mixture weight was heated to $165^{\circ} \mathrm{C}$, then transferred to the roller compaction mold of ( $300 \times 400 \times 70) \mathrm{mm}$ size and subjected to roller compaction. The applied load was $5 \mathrm{kN}$, and the required number of rollers passes to achieve the required target density was 56 which was obtained after many trials as per EN 12697 - 33, ${ }^{[17]}$. The slab samples were rejected from the roller compactor and removed from the mold after 24 hours. Core specimens of $63.5 \mathrm{~mm}$ in thickness and 101.6 $\mathrm{mm}$ in diameter were extracted from the slab samples. Specimens were prepared at optimum binder content of $4.7 \%$ and extra specimens were prepared at $0.5 \%$ asphalt below and above the optimum binder content. Specimens were subjected for strength properties determination such as Marshall stiffness which was calculated by dividing the Marshall stability in $(\mathrm{kN})$ by the Marshall flow in $(\mathrm{mm})$, the indirect tensile strength ITS $(\mathrm{kPa})$, and the double punching shear strength $(\mathrm{kPa})$. Specimens were tested in triplicate and the average value of each strength test was considered for analysis. Details of the trial samples and optimization of the rolling process could be referred to 
Sarsam and Khalid ${ }^{[18]}$.

\subsection{Testing of Asphalt Concrete Specimens}

The prepared asphalt concrete specimens by the aid of the three modes of compaction were tested for Marshall Stability and flow value at $60^{\circ} \mathrm{C}$ as per ASTM, 2016, double punching shear strength at $60^{\circ} \mathrm{C}$ As per Jimenez, ${ }^{[19]}$, and indirect tensile strength at $(60,40$, and 25$){ }^{\circ} \mathrm{C}$ as per ASTM ${ }^{[13]}$. Table 5 demonstrates the design bulk density implemented for preparing the asphalt concrete specimens for each asphalt binder content.

Table 5. The Implemented Bulk density for Asphalt Concrete

\begin{tabular}{cc}
\hline Asphalt binder content $\%$ & Bulk dry density $\mathrm{gm} / \mathrm{cm}^{3}$ \\
\hline 4.2 & 2.310 \\
4.7 & 2.350 \\
5.2 & 2.362 \\
\hline
\end{tabular}

\section{Results and Discussions}

\subsection{Influence of Compaction Mode on Indirect Tensile Strength}

Figure 1 demonstrates the influence of compaction mode and binder content on the Indirect Tensile Strength ITS of asphalt concrete when tested at $25^{\circ} \mathrm{C}$. It can be noticed that the roller compaction mode exhibits the lowest tensile strength regardless of the binder content as compared with other modes of compaction. This may be attributed to the orientation of aggregate particles and non-restriction on the movement of particles in the horizontal direction. Such behavior agrees with Xing et al. ${ }^{[4]}$. However, Marshall hammer compaction exhibits the highest tensile strength. This could be attributed to the restricted movement of aggregate particles within the mold. The highest tensile strength was obtained at optimum binder content of $4.7 \%$ regardless of the compaction mode. The tensile strength of asphalt concrete declines when the binder content increases or decreases by $0.5 \%$ than the optimum by ( 16.3 and 18.4$) \%$, (6.9 and 0.6$) \%$ and (4.7 and 23.6$) \%$ for hammer, gyratory and roller compacted mixtures respectively. On the other hand, the tensile strength of asphalt concrete prepared at optimum asphalt content, declines by (18.8 and 70.5) \% for gyratory and roller compacted specimens respectively as compared with that of hammer compacted specimens. Similar behavior was reported by Tarefder and Ahmad ${ }^{[7]}$.

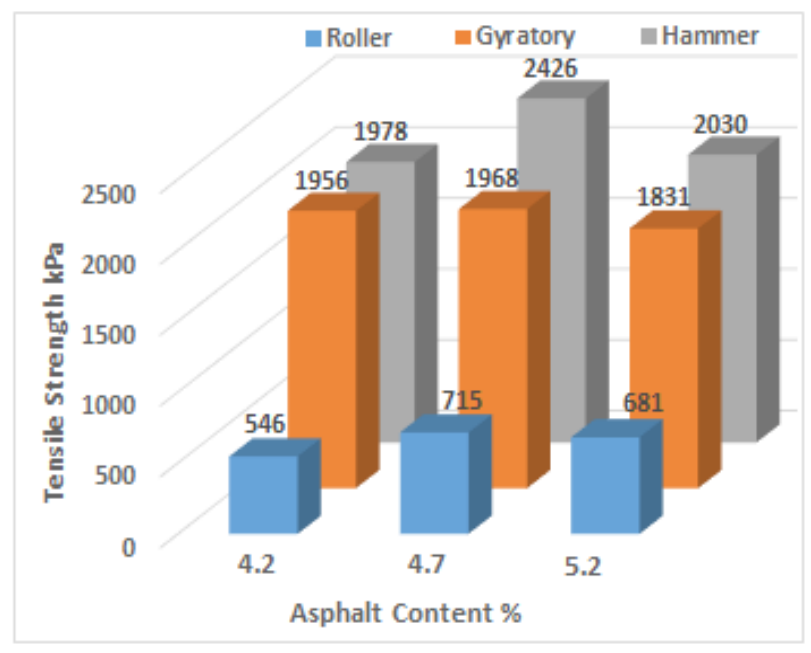

Figure 1. Influence of Binder Content on Tensile Strength

\subsection{Influence of Testing Temperature and Compaction Mode on Indirect Tensile Strength}

Figure 2 exhibits the influence of testing temperature on the indirect tensile strength of asphalt concrete specimens prepared with three modes of compaction. It can be observed that specimens prepared by gyratory compaction are less susceptible to the change in the testing temperature as compared with other modes of compaction. The tensile strength of asphalt concrete declines by $(93.8,61.8$, and 78.1$) \%$ for hammer, gyratory, and roller compacted specimens respectively when tested at $60{ }^{\circ} \mathrm{C}$ as compared to the case of testing at $25{ }^{\circ} \mathrm{C}$. Such finding agrees with Sarsam S. and Khalid ${ }^{[18]}$.

\subsection{Influence of Compaction Mode on Double Punch Shear Strength}

Figure 3 exhibits a significant variation in shear strength of asphalt concrete upon modes of compaction. It can be detected that as the binder content increase, the shear strength increases regardless of the compaction mode. This may be attributed to the fact that the asphalt mixture was designed based on Marshall method. The selected optimum binder content is selected based on the average of (maximum density, stability, and average voids content). Such optimum binder percentage may not satisfy the shear stress requirements. More binder seems to be required for lubricating the aggregate particles through the various modes of compaction to satisfy the shear requirements. The shear strength increases by $(0.8$ and 3.2) \%, (12.1 and 39.3) \%, and (3.8 and 27.1) \% when the binder content rises from(4.2 to 4.7 and 5.2) \% for gyratory, hammer, and roller compacted specimens 
respectively. At optimum asphalt content, the shear strength declines by (70.5 and 82.2) \% for hammer and roller compacted specimens as compared with that of gyratory compacted specimen. Such finding agrees with Al-ammari et al. ${ }^{[20]}$.

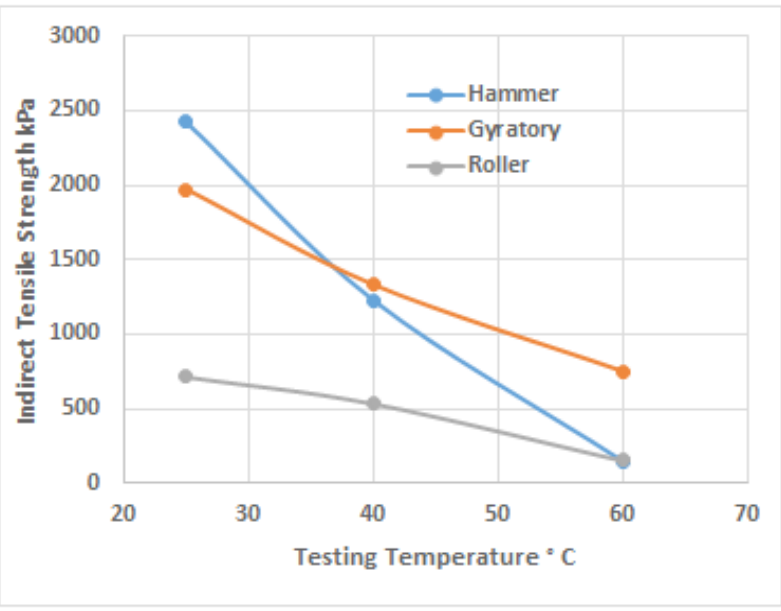

Figure 2. Influence of Testing Temperature on Tensile Strength

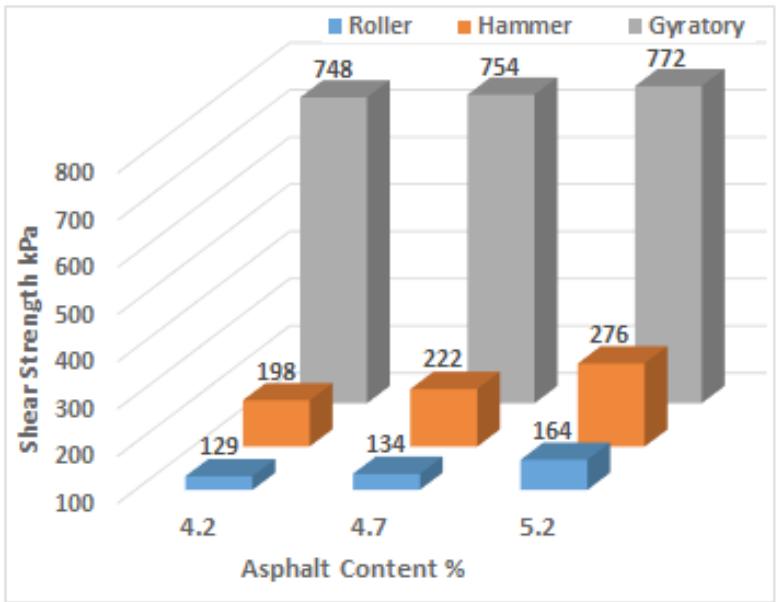

Figure 3. Influence of Binder Content on Shear Strength

\subsection{Influence of Compaction Mode on Marshall Stiffness}

Figure 4 demonstrates the variation in Marshall stiffness which was calculated by dividing Marshall stability in $(\mathrm{kN})$ by the flow value in $(\mathrm{mm})$ among compaction modes at various binder percentages.

It can be detected that gyratory compaction exhibits the highest Marshall stiffness among other modes of compaction. However, the optimum binder content exhibits the highest Marshall stiffness regardless of the compaction modes. The Marshall stiffness of asphalt concrete declines when the binder content increases or decreases by $0.5 \%$ than the optimum by ( 4 and 6.1 ) $\%$, (18.1 and 13.6) \% and (7.4 and 11.1) \% for hammer, gyratory and roller compacted mixtures respectively. At optimum binder content, Marshall stiffness declines by ( 10.2 and 44.8$) \%$ for hammer and roller compacted specimens as compared with that of gyratory compacted specimen. Such behavior agrees with the work which was reported by Wróbel et al. ${ }^{[12]}$.

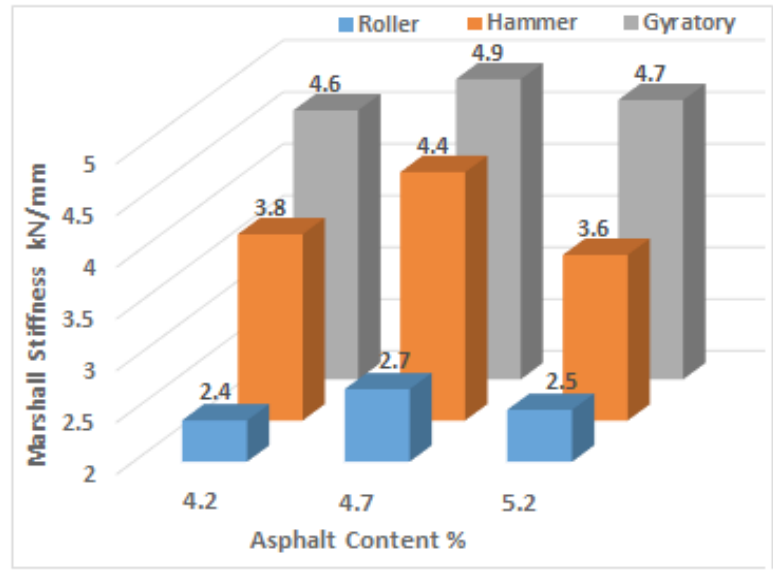

Figure 4. Influence of Binder Content on Marshall Stiffness

\section{Conclusions}

Based on the limitations of materials and the testing program implemented, the following conclusions may be addressed:

The indirect tensile strength of asphalt concrete declines when the binder content increases or decreases by $0.5 \%$ than the optimum by (16.3 and 18.4) \%, (6.9 and $0.6) \%$ and (4.7 and 23.6$) \%$ for hammer, gyratory and roller compacted mixtures respectively. The shear strength increases by (0.8 and 3.2) \%, (12.1 and 39.3) \%, and (3.8 and 27.1) \% when the binder content rises from(4.2 to 4.7 and 5.2$) \%$ for gyratory, hammer, and roller compacted specimens respectively. The Marshall stiffness of asphalt concrete declines when the binder content increases or decreases by $0.5 \%$ than the optimum by ( 4 and 6.1$) \%$, (18.1 and 13.6$) \%$ and (7.4 and 11.1) \% for hammer, gyratory and roller compacted mixtures respectively. However, specimens prepared by gyratory compaction are less susceptible to the change in the testing temperature and exhibit higher shear strength and Marshall stiffness as compared with other modes of compaction. On the other hand, specimens prepared by Marshall hammer compaction exhibit higher tensile strength as compared 
with other modes of compaction. It is recommended to consider the mode of compaction to suit the required design property of sustainable asphalt concrete mixture.

\section{References}

[1] Hartmán, A.; Gilchrist, M.; Walsh, G. (2001). Effect of mixture compaction on indirect tensile stiffness and fatigue. J. Transp. Eng. 127, 370-378.

[2] Vacková P., Valentin J., Kotoušová A. (2018). Impact of lowered laboratory compaction rate on strength properties of asphalt mixtures. Innovative Infrastructure Solution ;3: P.1-8. http://doi:10.1007/s41062017-0111-6.

[3] Huang L., Lin D., Luo H., Lin P. (2012). Effect of field compaction mode on asphalt mixture concrete with basic oxygen furnace slag. Construction and Building Materials. Volume 34, September. P. 1627, Elsevier. https://doi.org/10.1016/j.conbuildmat.2012.02.008.

[4] Xing, C.; Xu, H.; Tan, Y.; Liu, X.; Ye, Q. (2019). Mesostructured property of aggregate disruption in asphalt mixture based on digital image processing method. Constr. Build. Mater. 200, P. 781-789. https://doi.org/10.1016/j.conbuildmat.2018.12.133.

[5] Airey G., Collop A. (2014). Mechanical and structural assessment of laboratory and field-compacted asphalt mixtures. Int. J. Pavement Eng. 17: P. 50-63. http://doi:10.1080/10298436.2014.925551.

[6] Marcobal J., Lizárraga J., and Gallego J. (2019). Laboratory compaction study and mechanical performance assessment of half-warm mix recycled asphalt mixtures Containing 100\% RAP. Materials. 12, MDPI, 1992.

DOI: 10.3390/ma12121992 www.mdpi.com/journal/ materials.

[7] Tarefder, R.A.; Ahmad, M. (2016). Effect of compaction procedure on air void structure of asphalt concrete Measurement, 90, P. 151-157. https://doi. org/10.1016/j.measurement.2016.04.054.

[8] Woszuk A., Franus W. (2016). Properties of the Warm Mix Asphalt involving clinoptilolite and Na-P1 zeolite additives. Constr. Build. Mater. 114: P. 556-563. http://doi:10.1016/j.conbuildmat.2016.03.188.

[9] Radzi H., Muniandy R., Hassim S., Lawand T., Jakarni F. (2019). An overview of asphalt mix designs using various compactors. IOP Conf. Ser.: Mater. Sci. Eng. 512 012031. http://doi:10.1088/1757-
899X/512/1/012031.

[10] Pérez-Jiménez F, Martínez A, Miró R, Hernández-Barrera D and Araya-Zamorano L. (2014). Effect of compaction temperature and procedure on the design of asphalt mixtures using Marshall and gyratory compactors Construction and Building Materials 65 264-9.

[11] Cheung L.W., Dawson A.R. (2002). Effects of Particle and Mix Characteristics on Performance of Some Granular Materials. Transp. Res. Rec. J. Transp. Res. Board. 1787: P. 90-98. http://doi:10.3141/1787-10.

[12] Wróbel M., Woszuk A., and Franus W. (2020). Laboratory Methods for Assessing the Influence of Improper Asphalt Mix Compaction on Its Performance. Materials (Basel). MDPI. Jun; 13(11): 2476. http:// doi:10.3390/ma13112476.

[13] ASTM, American Society for Testing and Materials, ASTM: (2016). Road and Paving Material, VehiclePavement System, Annual Book of ASTM Standards, Vol. 04.03. www.astm.org.

[14] SCRB. (2003). State Commission of Roads and Bridges. Standard Specification for Roads \& Bridges, Ministry of Housing \& Construction, Iraq.

[15] Sarsam, S.I.; Al-Obaidi, M.K. (2014). Assessing the Impact of Various Modes of Compaction on Tensile Property and Temperature Susceptibility of Asphalt Concrete. Int. J. Sci. Res. Knowledge. 2, P. 297-305.

[16] Sarsam S. and Al-Obaidi M. (2014). Modeling the Impact of Various Modes of Compaction on Shear Property of Asphalt Concrete. Research Journal of modeling and simulation, (RJMS) Vol.1 No. (4), pp. 56-64, Sciknow publication Ltd. USA.

[17] EN. EN 12697 - 33, (2007). Bituminous Mixtures - Test Methods for Hot Mix Asphalt - part 33: Specimen prepared by Roller Compactor, European Committee for Standardization.

[18] Sarsam S. and Khalid M. (2016). Influence of compaction method on asphalt concrete quality. Lambert academic publishing, ISBN: 978-3-330-02415-1.

[19] Jimenez, R. A. (1974). Testing for Debonding of Asphalt from Aggregates, Transportation Research Record 515, TRB, National Research Council, Washington, D.C., P. 1-17.

[20] Al-ammari M., Jakarni F., Muniandy R., and Hassim S. (2019). The effect of aggregate and compaction method on the physical properties of hot mix asphalt. IOP Conf. Ser.: Mater. Sci. Eng. 512012003 https:// www.researchgate.net/publication/332622467. 